\title{
The Use of the Second-Generation Protein Kinase Inhibitors in Patients with Gastrointestinal Stromal Tumor with Failure to the Treatment with Imatinib
}

\author{
Francisco Eduardo Silva*, Ana Claudia Leite da Silva \\ Universidade Federal do Rio de Janeiro, South America
}

Submission: March 29, 2017; Published: March 30, 2017

*Corresponding author: Francisco Eduardo Silva, Universidade Federal do Rio de Janeiro, Rua BolÃ $\neg v a r, 54$ apto 402 - Copacabana, Rio de Janeiro, Brazil, South America, Tel: +55 21 98408-9924; Email: dr.francisco.eduardo@gmail.com

\begin{abstract}
Introduction: Gastrointestinal Stromal Tumor (GIST) is considered the most common mesenchymal tumor of the gastrointestinal tract. Approximately $85 \%$ of GISTs have mutations in proto-oncogene KIT encoding, a tyrosine kinase receptor. About $8 \%$ of GISTs are associated to mutations in the growth factor receptor alpha (PDGFRA) gene. The standard treatment of GIST is the surgical resection of the tumor. In cases of metastasis and tumor recurrence specific drugs as tyrosine kinase inhibitors are used. The first line treatment is Imatinib. Although the treatment with imatinib failed in some patients for the metastatic and relapsed treatment of GIST, the patients can to use other drugs, called second generation.
\end{abstract}

Discussion: One of the great advances in the diagnosis of GIST was the recognition through the immunohistochemistry of the c-Kit marker. The tyrosine kinase inhibitor, imatinib, has become the standard treatment for those, with high-risk resected GISTs and as first-line therapy in metastatic GIST. However, some patients fail imatinib treatment. Individuals with imatinib-resistant GIST have clear signs or symptoms of disease progression at the recommended starting dose of $400 \mathrm{mg} /$ day. After the disease progresses, doctors can increase the dose of imatinib to $800 \mathrm{mg}$ / day or start second-line treatment with other drugs (sunitinib, regorafenib, sorafenib).

Conclusion: Imatinib is the standard of care for patients with high-risk resected GIST and as first-line therapy in metastatic GIST. In cases of treatment failure with imatinib, second-class drugs can be used, but prospective studies of scientific quality are lacking to determine which second-class tyrosine kinase inhibitor should be used in each clinical situation.

Keywords: Gastrointestinal stromal tumors; Imatinib mesylate; Sunitinib malate; Kit proto-oncogene protein; Sorafenib; Regorafenib; Relapse tumor

\section{Introduction}

Gastrointestinal Stromal Tumor (GIST) is considered the most common mesenchymal tumor of the gastrointestinal tract and it accounts for about $1 \%$ of all malignant tumors. The worldwide incidence of GIST is estimated at 1-1.5 per 100,000 inhabitants and its prevalence is around 13 per 100,000 inhabitants. Population studies have shown that the mean age at diagnosis of GIST is 60 years old. There is no significant difference between individuals of both sexes. The predominant location of GIST is the stomach (55.6\%), followed by the small bowel $(31.8 \%)$, colorectal $(6 \%)$ and esophagus $(0.7 \%)$ and rarely can be found in the mesentery, omentum or retroperitoneum $[1,2]$.

Approximately $85 \%$ of GISTs have mutations in protooncogene KIT encoding a tyrosine kinase receptor. About $8 \%$ of
GISTs are associated with mutations in the growth factor receptor alpha (PDGFRA) gene. Surgical treatment is the standard therapy for GIST, with a complete resection of the tumor. Metastasis to the lymph nodes is rare. The overall 5-year survival rates for the primary resected disease are in the order of $50 \%$ to $55 \%$. GISTs do not respond to Radiotherapy and chemotherapy [3].

The discovery of the molecular mechanism that induces the mutation that will form GIST has helped in the development of specific therapies. It is noteworthy the rapid advances in the understanding of these tumors in their several aspects that allowed the use of drugs that act at molecular level (target therapies) interrupting or hindering tumor progression. Positive expression of tyrosine kinase (KIT) in Cajal cells is 
the determinant factor for the therapy of unresectable tumor, recurrent and metastatic tumors. The development of specific tyrosine kinase inhibitors has revolutionized the treatment of unresectabletumor and metastatic GIST. The first line treatment is Imatinib that is a selective inhibitor of KIT and PDGFRA [4]. However, some patients are resistant to imatinib and have side effects with imatinib. Other second-generation tyrosine kinase inhibitors have a broader spectrum of action. Second-generation tyrosine kinase inhibitors are being investigated for use in patients with failure treat with imatinib [5].

\section{Discussion}

The importance of GISTs is recognized because they are the most common mesenchymal tumors in the gastrointestinal tract. The GIST may occur from the esophagus to the anus. In addition, depending on the timing of the diagnosis, the evolution may not be favorable. A high degree of suspicion of the disease is required to establish the diagnosis. One of the great advances in the diagnosis of GIST was the recognition through immunohistochemistry of the c-Kit marker as a marker of these tumors, aiding in the understanding of its origin and in the treatment. Tyrosine kinase receptors represent targeted therapy in the presence of unresectable tumor, metastatic disease and often in relapses after surgical treatment. The advances in the understanding of the functioning aspects of these tumors allowed the use of drugs that act at molecular level (target therapies) acting directly on the tumor progression, hindering its evolution. Before to the use of targeted therapies, survival after detection of metastatic disease was generally less than 2 years [6].

GIST has recently been recognized as a clinicopathological entity separate from other mesenchymal tumors. The literature available until the late 1990 s did not provide an accurate description of the clinical behavior of GIST as well as an accurate diagnosis. The treatment of GIST has presented a paradigm shift in recent years with the detection of activating mutations in most of these tumors. This knowledge led to the development of targeted treatments that dramatically improved benefit and survival rates. The tyrosine kinase inhibitor, imatinib, has become the standard of treatment for those high-risk resected GISTs and as first-line therapy in metastatic GIST. Until the current days, there is no consensus regarding tyrosine kinase inhibitors as a neoadjuvant modality in the treatment of patients with localized disease.

However, some patients show innate resistance to imatinib. Another group of patients developed resistance despite a satisfactory initial response to imatinib. There is also a group of patients (less than 15\%) who do not demonstrate primary resistance to imatinib but present disease progression despite treatment. In addition, for those patients with metastatic disease, most will show tumor progression during the course of treatment with imatinib despite initial responses or stabilization of the disease. Usually occursdue to the emergence of resistant clones through the development of new KIT mutations, such as those that interfere with imatinib binding to kinase domains $[7,8]$. However, there is an increase in scientific interest in the use of tyrosine kinase with a broader spectrum of activity than imatinib. In adition, half of the patients will have experienced disease progression after 20 months with treatment with imatinib. Patients with GIST imatinib-resistant have clear signs or symptoms of disease progression at the recommended starting dose of $400 \mathrm{mg} /$ day.

After the disease progresses, doctors can increase the dose of imatinib to $800 \mathrm{mg} /$ day or start second-line treatment with other drugs (sunitinib, regorafenib, sorafenib). Sunitinib is standard second-line treatment, although its benefit over placebo for overall survival is relatively short and there are numerous potentially serious side effects [5]. Second-generation tyrosine kinase inhibitors with a broader action spectrum, such as sunitinib and sorafenib, have been investigated and have some benefit after failure of the imatinib treatment. Sunitinib is a tyrosine kinase inhibitor with antiangiogenic and antitumor effects. It has shown benefit in the imatinib-resistant population in a randomized, placebo-controlled study of its use in disease progression [9]. However, in the absence of randomized studies comparing the use of imatinib with sunitinib, no definitive conclusions can be drawn as to the superiority of sunitinib. Some pioneering studies demonstrate the use of sorafenib in patients who have demonstrated resistance to imatinib and sunitinib [10].

Regorafenib, a multidirectional and orally available tyrosine kinase inhibitor with antiangiogenic activity, has also demonstrated preclinical evidence of activity against a number of solid tumors. Other studies have proved that regorafenib is effective in GIST after failure of standard therapy with acceptable toxicity profile. The combined use of more than one anti-tyrosine kinase agents should be discouraged by the considerable potential for toxicity $[9,11,12]$.

\section{Conclusion}

Imatinib is the standard of care for the patients with highrisk resected GIST and as first-line therapy in GIST metastatic. However, with a number of second-generation agents with potential for treatment and stabilization of advanced disease are available for the use. Clinicians should consider time and sequencing issues to maximize the benefit of these treatments and the role of these new agents in refractory cases of imatinib. The toxicity assessment of these new drugs should be taken into account for their use in imatinib failure. There is still a shortage of prospective studies with the scientific quality evaluated to determine which second-class tyrosine kinase inhibitor should be used. Each clinical situation and each type of patient, either by tumor relapse refractory to the use of imatinib as well as the evolution of the disease despite the Treatment, the secondgeneration drugs can to use carefully. 


\section{References}

1. Nishida T, Blay JY, Hirota S, Kitagawa Y, Kang YK (2016) The standard diagnosis, treatment, and follow-up of gastrointestinal stromal tumors based on guidelines. Gastric Cancer 19(1): 3-14.

2. Søreide K, Sandvik OM, Søreide JA, Giljaca V, Jureckova A, et al. (2016) Global epidemiology of gastrointestinal stromal tumours (GIST): A systematic review of population-based cohort studies. Cancer Epidemiol 40: 39-46.

3. Ma GL, Murphy JD, Martinez ME, Sicklick JK (2015) Epidemiology of gastrointestinal stromal tumors in the era of histology codes: results of a population-based study. Cancer Epidemiol Biomarkers Prev 24(1): 298-302.

4. Hislop J, Quayyum Z, Elders A, Fraser C, Jenkinson D, et al. (2011) Clinical effectiveness and cost-effectiveness of imatinib dose escalation for the treatment of unresectable and/or metastatic gastrointestina stromal tumours that have progressed on treatment at a dose of 400 mg/day: a systematic review and economic evaluation. Health Technol Assess 15(25): 1-178.

5. Shinagare AB, Jagannathan JP, Kurra V, Urban T, Manola J, et al. (2014) Comparison of performance of various tumour response criteria in assessment of regorafenib activity in advanced gastrointestinal stromal tumours after failure of imatinib and sunitinib. Eur J Cancer 50(5): 981-986.

6. Silva FE, Ascoly MH, Scofano V, ArakakiJrN, Reis O, Sá MAGS (2004) Tumores Estromais Gastrointestinais - Gist: Relato de um Caso. Rev Bras Coloproct 24(2): 159-164.
7. Marynen P, Debiec-Rychter (2006) Efficacy of the kinase inhibitor SU11248 against gastrointestinal stromal tumor mutants refractory to imatinib mesylate. Clin Cancer Res 12(8): 2622-2627.

8. Heinrich MC, Maki RG, Corless CL, Antonescu CR, Harlow A, et al. (2008) Primary and secondary kinase genotypes correlate with the biological and clinical activity of sunitinib in imatinib-resistant gastrointestinal stromal tumor. J ClinOncol 26(33): 5352-5359.

9. Demetri GD, Reichardt P, Kang YK, Blay JY, Rutkowski P, et al. (2013) Efficacy and safety of regorafenib for advanced gastrointestinal stromal tumors after failure of imatinib and sunitinib (GRID): an international, multicenter, randomized, placebo-controlled, phase 3 trial. Lancet 381(9863): 295-302.

10. Montemurro M, Gelderblom H, Bitz U, Schütte J, Blay JY, et al. (2013) Sorafenib as third- or fourth-line treatment of advanced gastrointestinal stromal tumor and pretreatment including both imatinib and sunitinib, and nilotinib: A retrospective analysis. Eur J Cancer 49(5): 1027-1031.

11. Rutkowski P, Stępniak J (2016) The safety of regorafenib for the treatment of gastrointestinal stromal tumors. Expert Opin Drug Saf 15(1):105-16

12. Poole CD, Connolly MP, Chang J, Currie CJ (2015) Health utility of patients with advanced gastrointestinal stromal tumors (GIST) after failure of imatinib and sunitinib: findings from GRID, a randomized double blind, placebo-controlled phase III study of regorafenib versus placebo. Gastric Cancer 18(3): 627-634.

\section{Your next submission with Juniper Publishers will reach you the below assets}

- Quality Editorial service

- Swift Peer Review

- Reprints availability

- E-prints Service

- Manuscript Podcast for convenient understanding

- Global attainment for your research

- Manuscript accessibility in different formats

( Pdf, E-pub, Full Text, Audio)

- Unceasing customer service

Track the below URL for one-step submission https://juniperpublishers.com/online-submission.php 